\title{
LASCO SOHO OBSERVATIONS OF MATTER FLOWS IN THE SOLAR CORONA
}

\author{
A. B. Delone, G. A. Porfir'eva, G. V. Yakunina \\ State Sternberg Astronomical Institute, \\ Moscow University, Moscow, 119899, Russia, \\ yakunina@sai.msu.ru \\ (Received December 19, 2006)
}

\begin{abstract}
A brief review on coronal matter velocities in the picture plane is presented using the results of observations of LASCO SOHO. General features of the moving coronal formations and their velocities are systematized. On the distances of $(2-6) R_{\odot}$ events have been revealed with coronal plasma motions both to the Sun and from its surface with velocities from dozens to hundreds of $\mathrm{km} \cdot \mathrm{s}^{-1}$. A possible physical nature of the events is discussed.

Key words: sun, corona, matter motions.
\end{abstract}

PACS number(s): 96.60.Pb, 96.60.Qc

\section{INTRODUCTION}

The solar corona is well known to be a dynamical phenomenon. According to observations from the ground and space turbulent and directed mass motions in the low corona at heliocentric distances $r$ up to $1.25 R_{\odot}$ have the velocities in the range from several to dozens of $\mathrm{km} \cdot \mathrm{s}^{-1}[1-3]$. The turbulent velocities are determined from the Doppler half-widths of spectral line profiles. Doppler shifts of the spectral lines give us a possibility to find the line-of-sight velocities of moving plasma. Series of images with a high temporal resolution are used to study the evolution of dynamic events such as eruptive prominences, mass ejections during solar flares and coronal rain in projection on the picture plane. Continuous flows of the solar plasma from the Sun (called solar wind) with gradually increasing velocities reaching the values of $400-800 \mathrm{~km} \cdot \mathrm{s}^{-1}$ near the Earth orbit are studied from cosmic stations and observed at distances much grater than 1 a. u. (astronomical unit).

Since 1999 observations with the Large Spectrometric Coronograph (LASCO) at the Solar and Heliospheric Observatory (SOHO) have given a rich information on motions of coronal plasma in high layers at the heliocentric distances $\mathrm{r}$ in the range from 2 to $6 R_{\odot}$ and higher $[4 \div 12]$. In our paper results of the observations in white light with the LASCO C2 coronograph on the SOHO spacecraft are reviewed. Different types of features with different velocities, directed both to and from the Sun, are demonstrated. Some plasma pieces are seen moving along narrow paths and some matter motions occupy a wide range of the position angles. Different events seem to be caused by different physical mechanisms. Their possible nature is briefly discussed.

\section{OBSERVATIONS AND METHOD}

The LASCO instrument on the SOHO consists of three coronographs with overlapping fields of view and different spatial resolution: $\mathrm{C} 1\left(1.1-3 R_{\odot}, 11^{\prime \prime}\right), \mathrm{C} 2\left(2-6 R_{\odot}\right.$, $\left.24^{\prime \prime}\right)$, and C3 $\left(4-30 R_{\odot}, 112^{\prime \prime}\right)$. The C2 and C3 coronographs record the white-light coronal emission, being the photospheric light in the optical region, scattered on free electrons in the solar corona. Data from the LASCO $\mathrm{C} 2 / \mathrm{SOHO}$ are used to investigate matter motions in high corona mainly on the distances of $2-6 R_{\odot}$. To follow a relation of coronal mass ejection (CME) events with the corresponding active region, images of the full solar disc up to $r 1.6 R_{\odot}$ in Fe XII $\lambda 195 \AA\left(T \approx 1.6 \times 10^{6} \mathrm{~K}\right)$, obtained with Extra-Ultra-Violet Imaging Telescope (EIT) on SOHO, were used.

The intensity of the white corona is known to decrease strongly with the heliocentric distance $r$ and depending on the concrete case the intensity of the moving features is $(7-30) \%$ greater than the surrounding coronal structures intensity. Hence the events under consideration are faint by their intensities. To increase the contrast of the investigated coronal features a special method of difference images is used. To emphasize the moving feature the previous image is subtracted from the current one. This results in a running difference image. The time lag can vary from $15-20^{m}$ to several hours depending on the event.

To emphasize the background coronal structures, which are relatively stable, a fixed base image was used for the subtraction. This fixed image represents the image with minimum coronal intensity during the month time interval around of the current moment. The final image was composed by combining the two difference images. Such a combination provides the best appearance of the moving feature on the background of the nearby coronal structures. The places, where the density has increased, are seen as white, and the places, where the density has decreased, look black. If there is no change in mass then these sites are grey of different tones.

Having the running difference images, obtained at the time intervals of about $15-20^{m}$, height/time maps are made using the technique, suggested by J. H. Walters and described by Sheeley et al. [5]. Radial strips of the widths of about $2-10^{\circ}$ cut out at the position angle, where the event has occurred, are orientated vertically and stacked 
chronologically one after another. White/black "patchy" tracks are outlined on the maps. Sometimes two or more tracks are seen. The tracks show how different coronal features move along concrete radial directions with time. Analysing these maps, velocities and accelerations of the moving matter are calculated depending on the time, expressed in hours or days of the year. A polynomial, fitting the measured height/time track, is found and the velocities and accelerations are calculated by the differentiation of the polynomial.

\section{DIFFERENT TYPES OF CORONAL MOTIONS AND THEIR CHARACTERISTICS}

As is demonstrated by LASCO observations most of the matter is seen to move away from the Sun. However numerous cases have been revealed when some features are returning back toward the Sun. Sometimes a fraction of the matter is moving to the Sun and simultaneously another part is flowing upwards, starting at the same space point as the inflow does. It seems surprising that inflowing events start only at the heights laying in the range from about $3.0 R_{\odot}$ to about $5.5 R_{\odot}$. The start points have been never seen higher than $6 R_{\odot}$ and lower than $2.5 R_{\odot}$. One must remember that here the height means really the height projected on the picture plane.

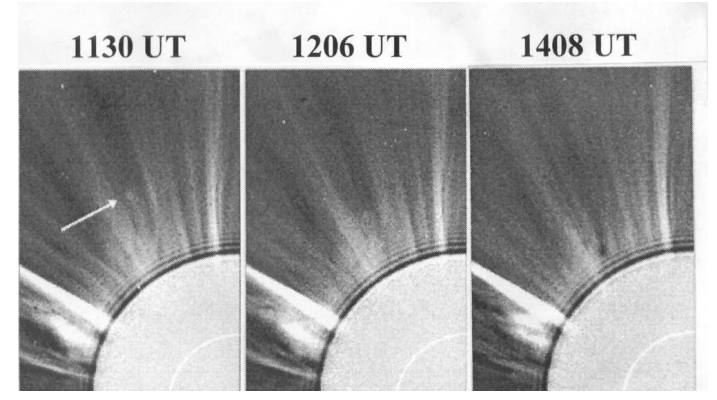

Fig. 1. Images of the faint column of intensity on 12 June, 2000 , moving inward. The top of the column is indicated by the arrow at 11:30 UT. The northeast quadrant of the LASCO C2 field of view is shown. The edge of the occulting disk is at about heliocentric distance of $2 R_{\odot}$, according to Fig. 1 from $[8]$

Observed events vary by their shapes, behaviour, velocities and direction of movement. There are both inflows and outflows. As was indicated by Sheeley and Wang in [8] coronal inflows moving along narrow linear paths and looking like "sinking plasma columns" are very numerous events. Fig. 1 (all the images are used with the permission of the authors in private communications in answer on our request) shows such an event occurring on 12 June, 2000, according to Fig. 1 from [8]. A faint emission column, the upper end of which is indicated by the arrow, is moving inward (Fig. 1: 11:30 UT and 12:06 UT). The light/dark boundary seems to be a top of the sinking plasma column. When it approaches the height near $2 R_{\odot}$, the dark region behind it begins to take a teardrop shape with the tail, turning away from the Sun, as it is seen at 14:08 UT (Fig. 1). The intensity of the sinking column itself becomes fainter in comparison with the surrounding corona. The white semicircle has the radius $r=2 R_{\odot}$ and represents the occulting disc of the LASCO C2 coronograph.

These events seem to occur spontaneously and have no outflowing components, which may be invisible simply because of their extraordinary faint intensity. The scenario of movements varies strongly. The matter can move uniformly or with an acceleration or deceleration or changing the values and signs of its characteristics.

Fig. 2 shows the downward track for the event observed on 12 June, 2000, corresponding to the matter inflow along the path at the position angle of $N 63^{\circ} \mathrm{E}$, i. e. the position angles are counted from the north to the east. The track is a projected radial distance in solar radii (along the $Y$-axis) as a function of time in days of the year (put on the $X$-axis). A matter outflow would be represented by an upward track. For the case of 12 June, 2000 the velocity increased (by its absolute value) from $-40 \mathrm{~km} \cdot \mathrm{s}^{-1}$ to $-75 \mathrm{~km} \cdot \mathrm{s}^{-1}$ and then decreased practically to zero, which is calculatable from the track on Fig. 2. The acceleration values change from $-6.5 \mathrm{~m} \cdot \mathrm{s}^{-2}$ at the start to $+6.5 \mathrm{~m} \cdot \mathrm{s}^{-2}$ at the end, being equal approximately to zero in the middle of the path. The sign minus means that the velocity or acceleration is directed inward to the Sun and the sign plus is used for the velocity and deceleration in the case of outflows.

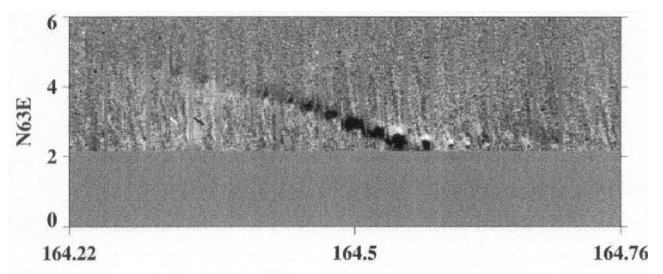

Fig. 2. Height/time map for the event on 12 June, 2000, made from consecutive radial slices, cut along the position angle $\mathrm{N} 63^{\circ} \mathrm{E}$. The downward track, visible clear on the map, corresponds to the plasma column moving inward and shown in Fig. 1, according to Fig. 2 from [8].

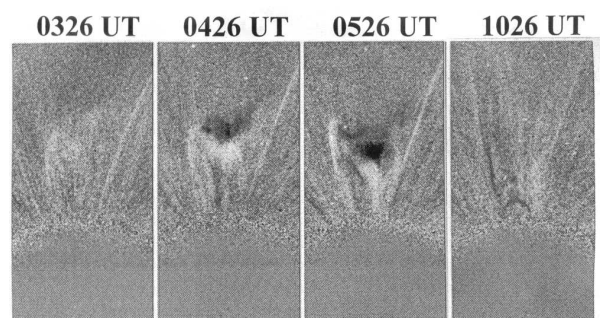

Fig. 3. Images of the event on 19 October, 1999, looking like falling curtain, according to Fig. 12 from [8].

Large structures, occupying a wide range of position angles and looking like "falling curtains", are another kind of the inflows, observed with the LASCO C2. They are more intensive than sinking columns. Difference images of the event, being a falling curtain and occurring on 19 October, 1999, are shown in Fig. 3, according to Fig. 12 
from [8]. This descending material seems to occur at a short-lived sector boundary of the magnetic field. The leading part of the feature looks as white and the trailing as dark, indicating the density enhancement in the front (see Fig. 3: 04:26 UT and 05:26 UT). This structure followed some large system of loops, rising slowly with the velocity of about $30 \mathrm{~km} \cdot \mathrm{s}^{-1}$ from the edge of the occult- ing disc on the C2 coronograph visible on Fig. 3: 03:26 UT. Then the central part of the rising system began to fall down and at the end of its path was transformed into a series of fading dark loops (Fig. 3: 10:26 UT). In this case a fraction of the slowly rising large loop system was collapsed suddenly and returned back to the Sun.
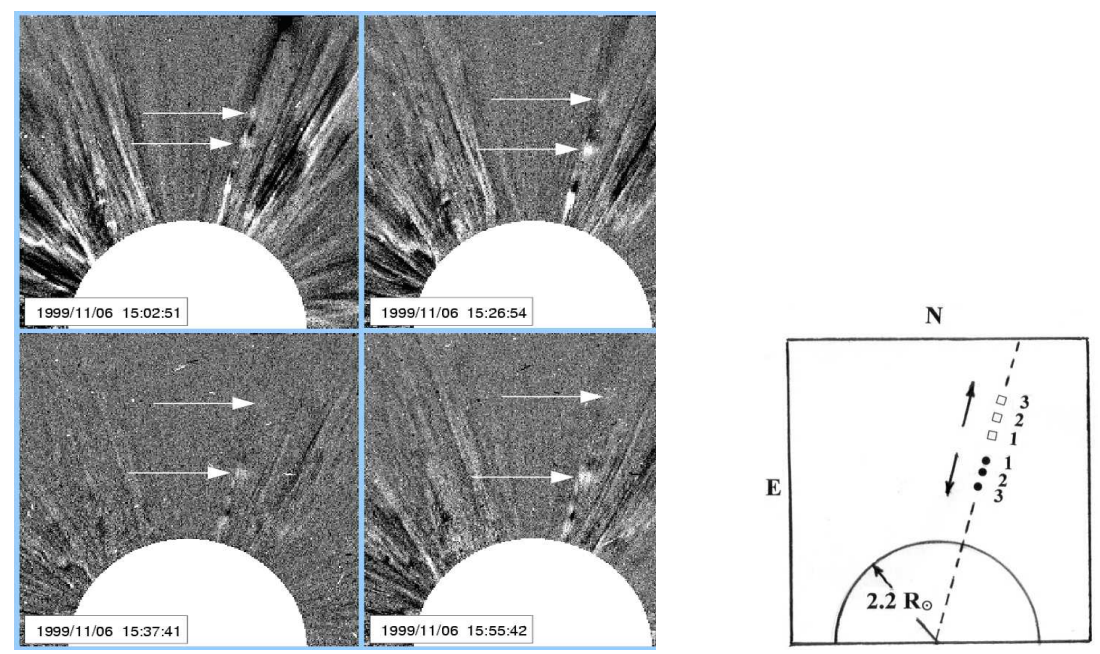

Fig. 4. Images of the bidirectional event on 6 November, 1999, according to Fig. 1 from [9] are on the left side. Schematic drawing of the location of the plasma blobs for three time moments 15:02:51 UT, 15:26:54 UT and 15:55:42 UT is on the right side. The flowing away coronal plasma blobs are indicated by the arrows. The semicircle represents a half of the solar occulting disc on the LASCO C2 coronograph. The boundary of the occulting disc is about $2 R_{\odot}$, according to Fig. 1 from [9].

A special type of events has been analysed by Simnett [9]. In the period of 1998-2002 40 events were discovered, when plasma blobs were visible both as an inflow and an outflow along the same radial direction. Such events are called bidirectional ones. An example of such an event is shown in Fig. 4, where the event on 6 November, 1999 is demonstrated. On the left side the images at four time moments are given according to Fig. 1 from [9]. The plasma blobs are indicated by the white arrows. Comparing difference images, recorded at different time moments, one can see that one blob is moving upwards and the other downwards. The front edge is visible as white and the trailing edge as black both for the outflow and inflow. On the right side in Fig. 4 we present a schematic drawing showing the location of the blobs at three time moments. The opposite directions of the plasma blobs movement are indicated by the black arrows. For 40 events the birth of such pairs occurs mainly at the heliocentric distances $3.1 R_{\odot} \leq r \leq 4.4 R_{\odot}$. The mean height of starting is about $3.7 R_{\odot}$. The outflowing matter moves usually with a higher velocity than the descending one does. The average difference in the up/down speeds equals $112 \mathrm{~km} \cdot \mathrm{s}^{-1}$. The least recorded value was $28 \mathrm{~km} \cdot \mathrm{s}^{-1}$ and the greatest $364 \mathrm{~km} \cdot \mathrm{s}^{-1}$. All these blobs seem to move with invariable velocities along narrow paths.

However some bidirectional events occupy a wide range of the position angles. An example of such features for the event on 24 October, 2000 is shown in Fig. 5 according to Fig. 14 from [8]. There are seen two large arches, indicated by the arrows. One of them is ascending and the other is descending from the projected point of the origin near $r \approx 4 R_{\odot}$. They both occupy a wide range of position angles. The running difference images are taken from the observation with the LASCO C2 coronograph (see Fig, 5: 1726-1650 UT and 1826-1750 UT). The occulting disc of the $\mathrm{C} 2$ coronograph is seen. The upper arch moved fast with the initial speed of about $180 \mathrm{~km} \cdot \mathrm{s}^{-1}$ and acceleration of about $7 \mathrm{~m} \cdot \mathrm{s}^{-2}$, and soon left the field of view of the $\mathrm{C} 2$ coronograph, continuing to expand past $14 R_{\odot}$ through the C3 coronograph field of view (Fig. 5: 23:18-22:18 UT, the occulting disc of the C3 coronograph is visible). The inward moving matter started with the velocity of about $-100 \mathrm{~km} \cdot \mathrm{s}^{-1}$ and constant deceleration of $-4 \mathrm{~m} \cdot \mathrm{s}^{-2}$. Both arches are convex in the direction of their motion. Between them a depleted region is clearly visible. The front edges of the arches are observed as white with black shadows behind. This event was related perhaps with a large coronal hole existing at that time [7].

A special type of events at high corona, being returning matter motions, from central regions of coronal mass ejections (CME), is investigated by Wang and Sheeley [11]. An example of such events is shown in Fig. 6 according to Fig. 3 from [11]. The ascent and subsequent fallback of a twisted CME core structure was recorded on 6 March, 2000 with the LASCO C2 coronograph. In Fig. 6 one can see how a relatively bright and compact core structure ascends to a height of about $3.5 R_{\odot}$ and then falls back toward the Sun. The feature has a twisted appearance being a significant fraction of the total 
matter of the CME. The CME was of diffuse consistence and quickly passing though the field of view of the $\mathrm{C} 2$ coronograph is not visible in the Fig. 6 . This event seems to be initiated by a filament eruption with the velocity greater than $150 \mathrm{~km} \cdot \mathrm{s}^{-1}$ from the solar surface, as is demonstrated by Wang and Sheeley in [11], by comparing $\mathrm{LASCO} / \mathrm{SOHO}$ and $\mathrm{EIT} / \mathrm{SOHO}$ data.

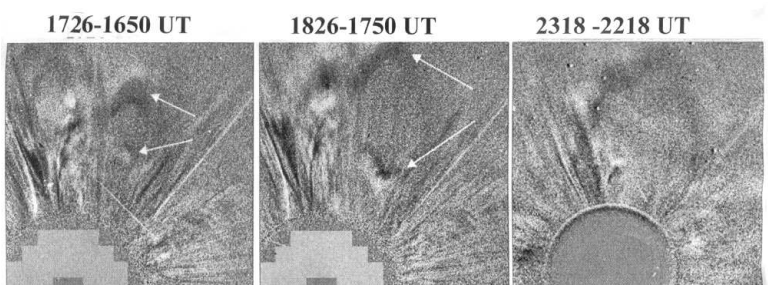

Fig. 5. Images of large arches on 24 October, 2000, flying away with different velocities and indicated by the arrows. At the first two time moments (17:26 and 18:26 UT) both arches are seen in the field of view of the LASCO C2 coronograph. The edge of the occulting disc is at about $2 R_{\odot}$. At 23:18 UT only the outflying arch is visible in the C3 coronograph field of view up to approximately $12 R_{\odot}$. The edge of the occulting disc is about $4 R_{\odot}$, according to Fig. 14 from [8].

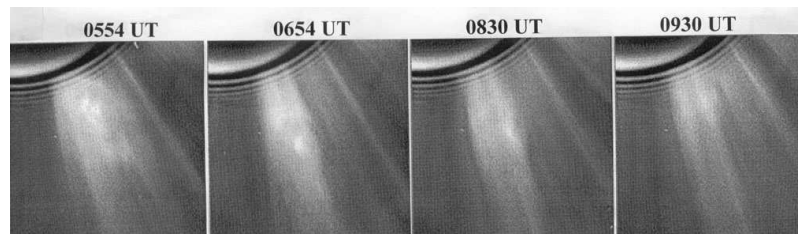

Fig. 6. Images, demonstrating the ascent to a height of about $3.5 R_{\odot}$ and subsequent descent of a twisted compact structure, being a significant fraction of the CME core on 6 March, 2000, according to Fig. 3 from [11].

The other example of the CME core fallback is demonstrated in Fig. 7 according to Fig. 1 from [11]. It is seen that a domeshaped structure reaches the maximum height of about $3.5 R_{\odot}$ and then it begins suddenly to fall down toward the Sun. The collapse begins approximately two hours later after the leading front of the CME has passed the field of view of the $\mathrm{C} 2$ coronograph.

In [11] about 20 fallback events, observed during 19982001 with the LASCO and associated with CMEs pas- sages, have been systematized. In all considered cases a significant fraction of the CME core after ascending to heights of about $2.5-6 R_{\odot}$ collapses and returns back to the Sun. The upward velocities of the associated CMEs are relatively slow and lie in the range from about $250 \mathrm{~km} \cdot \mathrm{s}^{-1}$ to $450 \mathrm{~km} \cdot \mathrm{s}^{-1}$. These CMEs move often with faint decelerations as it is clear from an analysis of their trajectories. Therefore it is not surprising that some part of the matter from the inner CME core cannot reach the escape velocity value and stays associated with the Sun by the gravitation and magnetic tense forces. Such a volume of the matter, that cannot flow upwards because of its insufficient velocity, some time later is often pushed out by subsequent outflows, rising from beneath, and after all leave the Sun, being carried out by faster plasma streams or ejections and particularly by the solar wind. The CME core structures ascend with the velocities of about $+(100-400) \mathrm{km} \cdot \mathrm{s}^{-1}$ that are a little smaller than the speeds of the front edges of CMEs and return with some smaller velocities of about $-(50-200) \mathrm{km} \cdot \mathrm{s}^{-1}$.

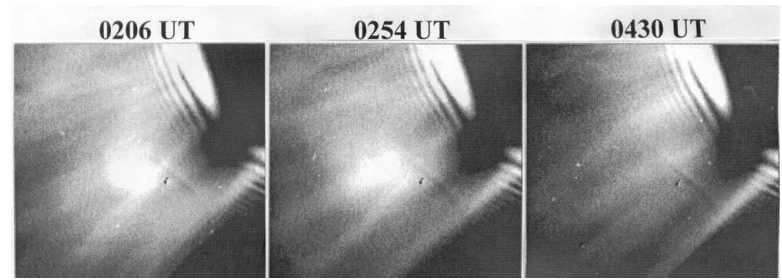

Fig. 7. Images, demonstrating the core fallback during the CME observed with the LASCO C 2 on 7 April, 1999 at the southeast direction, according to Fig. 1 from [11].

Examples of different tracks of matter, observed with the LASCO during coronal events of different types, occurring in the high corona, are shown schematically in Fig. 8. The projected heliocentric distances in solar radii $R_{\odot}$ are presented on the $Y$-axis and the duration of the events in hours is given along the $X$-axis. The bidirectional events, investigated by Simnett in 2004 [9], existed during the time interval of about two hours (Fig. 8,a). Such events as sinking columns are observed during many hours (Fig. 8,b). The fallback events during CMEs can be long duration events (time interval of 10-12 hours) and short duration events (time interval of 5-6 hours) as demonstrated in Fig. 8,c.
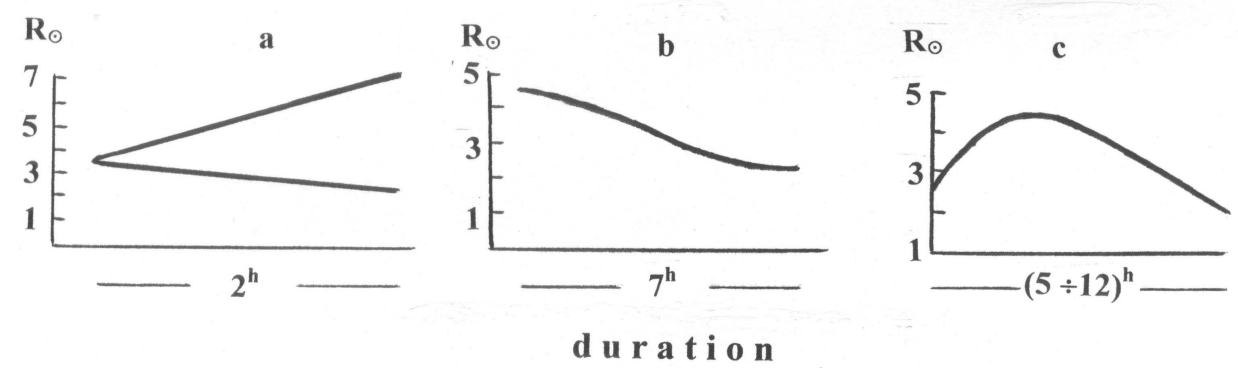

Fig. 8. Schematic drawings of different type tracks of moving coronal plasma: a) flying away upwards and downwards along a radial direction; b) descending down along a radial direction with an acceleration and subsequent deceleration; c) fallback of a CME core fraction along a radial direction. 
The results of the observations with the LAS$\mathrm{CO} / \mathrm{SOHO}$ are collected by us in Table 1 . The date, type of the event such as bidirectional (narrow or wide relative to position angles), sinking column or falling curtain, that are characterized by a narrow path or motion through a wide range of position angles correspondingly, and rising and subsequent falling back of a CME core fraction are given in the first and second columns. The heights of the events are demonstrated in the third column. For the bidirectional events the range of their origin heights and for other cases the range of the heights, where the events were visible, is given. The velocities and accelerations, directed upwards $\left(V_{\mathrm{u}}\right.$ and $\left.A_{\mathrm{u}}\right)$ and downwards $\left(V_{\mathrm{d}}\right.$ and $\left.A_{\mathrm{d}}\right)$ are demonstrated with their signs in the forth and fifth columns correspondingly. When the motion is changeable, then the values of the velocities and accelerations in the beginning $\left(V_{\mathrm{b}}\right.$ and $\left.A_{\mathrm{b}}\right)$, at the end of the path $\left(V_{\mathrm{e}}\right.$ and $\left.A_{\mathrm{e}}\right)$ and during maximum phase $\left(V_{\max }\right)$ are indicated. Analogically symbols $V_{\mathrm{db}}$ and $V_{\mathrm{de}}$ are used for plasma motions directed downwards at the beginning and at the end of tracks. Symbol $V_{\mathrm{ub}}$ means the upward velocity at the beginning of the path.

For the 40 bidirectional (up/down) pairs, investigated by Simnett [9], the ranges of the velocities are given separately for upwards and downwards movements and we must remember, that in these cases the motion was possible to consider as uniform. The upward speeds are greater than downwards ones and the average difference of them is equal to $112 \mathrm{~km} \cdot \mathrm{s}^{-1}$. The mean height where the events origin is evaluated to be about $3.7 R_{\odot}$. The duration of the events is given in the sixth column. For the fallback events during CME, that were investigated by Wang and Sheeley [11], the range of duration is given. The references are indicated in the last column. The frequency of the bidirectional events is one a week, but really more frequent, as it is discussed in [9]. The events, being sinking columns, are one an hour and flowing away arches occur several times a month. The frequency of different type events depends on the phase of the solar activity cycle. All events and especially CMEs (and consequently associated core fallbacks) are more frequent during the maximum of the solar activity.

\begin{tabular}{|c|c|c|c|c|c|c|c|c|}
\hline Date & Event type & $\begin{array}{c}\text { Height, } \\
R_{\odot}\end{array}$ & \multicolumn{2}{|c|}{ Velocity, km/s } & \multicolumn{2}{|c|}{ Acceleration, $\mathrm{m} / \mathrm{s}^{2}$} & \begin{tabular}{|c|} 
Dura- \\
tion, \\
hours \\
\end{tabular} & Ref. \\
\hline \begin{tabular}{|l|} 
V 1998 \\
XI 2002 \\
\end{tabular} & Bidirectional & $3.1 \div 4.4$ & $\begin{array}{l}V_{\mathrm{d}} \\
V_{\mathrm{u}} \\
\end{array}$ & $\begin{array}{r}-(42 \div 169) \\
(91 \div 370) \\
\end{array}$ & & & $\geq 2$ & [9] \\
\hline $\begin{array}{l}24 \mathrm{X} \\
2000\end{array}$ & $\begin{array}{l}\text { Bidirectional } \\
\text { arches }\end{array}$ & 4.0 & $\begin{array}{l}V_{\mathrm{d}} \\
V_{\mathrm{u}} \\
\end{array}$ & $\begin{array}{r}-100 \\
180 \\
\end{array}$ & $\begin{array}{l}A_{\mathrm{d}} \\
A_{\mathrm{u}}\end{array}$ & $\begin{array}{r}-4 \\
+7 \\
\end{array}$ & $\begin{array}{l}2 \\
6 \\
\end{array}$ & [8] \\
\hline $\begin{array}{l}12 \mathrm{VI} \\
2000\end{array}$ & Sinking column & $4.5 \div 2.2$ & $\begin{array}{l}V_{\mathrm{db}} \\
V_{\max } \\
V_{\mathrm{de}}\end{array}$ & $\begin{array}{r}-40 \\
-75 \\
0\end{array}$ & $\begin{array}{l}A_{\mathrm{b}} \\
A_{\mathrm{e}}\end{array}$ & $\begin{array}{l}-6.5 \\
+6.5\end{array}$ & 7 & [8] \\
\hline \begin{tabular}{|l|}
2 II \\
2000
\end{tabular} & Sinking column & $4.5 \div 2.2$ & $\begin{array}{l}V_{\mathrm{db}} \\
V_{\max } \\
V_{\mathrm{de}} \\
\end{array}$ & $\begin{array}{r}-40 \\
-57.5 \\
0 \\
\end{array}$ & $\begin{array}{l}A_{\mathrm{b}} \\
A_{\mathrm{e}}\end{array}$ & $\begin{array}{l}-4.1 \\
+7.0 \\
\end{array}$ & 7 & [8] \\
\hline $\begin{array}{l}25 \mathrm{X} \\
1999\end{array}$ & Sinking column & $4.0 \div 2.0$ & \begin{tabular}{|l|}
$V_{\mathrm{db}}$ \\
$V_{\mathrm{de}}$
\end{tabular} & $\begin{array}{l}-75 \\
-10\end{array}$ & $A_{\mathrm{b}}$ & +1.9 & 7 & {$[8]$} \\
\hline $\begin{array}{l}13 \mathrm{IV}- \\
14 \mathrm{IV} \\
2000 \\
\end{array}$ & $\begin{array}{l}\text { Sinking column } \\
\text { CME }\end{array}$ & $4.5 \div 2.5$ & $\begin{array}{l}V_{\mathrm{db}} \\
V_{\mathrm{de}} \\
V_{\mathrm{ub}}\end{array}$ & $\begin{array}{r}-70 \\
-40 \\
500 \div 600 \\
\end{array}$ & & & & [8] \\
\hline $\begin{array}{l}18 \mathrm{X}- \\
19 \mathrm{X} \\
1999\end{array}$ & $\begin{array}{l}\text { Ascending loops } \\
\text { and } \\
\text { Falling curtain }\end{array}$ & $\begin{array}{l}3.0 \div 4.0 \\
4.0 \div 2.2\end{array}$ & $V_{\mathrm{ub}}$ & +30 & & & & [8] \\
\hline $\begin{array}{l}1998- \\
2001\end{array}$ & $\begin{array}{l}\text { CME } \\
\text { Ascent and } \\
\text { descent of the } \\
\text { CME core }\end{array}$ & $\begin{array}{l}2.0 \div 6.0 \\
6.0 \div 2.0\end{array}$ & $\begin{array}{l}V_{\mathrm{ub}} \\
V_{\mathrm{ub}} \\
V_{\mathrm{de}}\end{array}$ & $\begin{array}{r}250 \div 450 \\
100 \div 400 \\
-(50 \div 200)\end{array}$ & $\begin{array}{l}A_{\mathrm{b}} \\
A_{\mathrm{e}}\end{array}$ & $\begin{array}{r}-10 \div 30 \\
-(20 \div 100)\end{array}$ & $5 \div 14$ & {$[11]$} \\
\hline
\end{tabular}

Table 1.

\section{DISCUSSIUON}

Different events associated with inflowing and outflowing coronal plasma at the heights of about $2-6 R_{\odot}$ were considered. Analysing the data, given in Table 1, we see, that characteristics of the motions vary strongly. The projected velocities take values in the range from $-200 \mathrm{~km} \cdot \mathrm{s}^{-1}$ to $+400 \mathrm{~km} \cdot \mathrm{s}^{-1}$ and accelerations from $+30 \mathrm{~m} \cdot \mathrm{s}^{-2}$ to $-100 \mathrm{~m} \cdot \mathrm{s}^{-2}$. The events are observed dur- ing time intervals being from $2 \mathrm{~h}$ to $14 \mathrm{~h}$. The events are often occur at sector boundaries of the solar magnetic fields or coronal holes, where oppositely directed magnetic fields are pushed together, being sheared by motions at the photospheric levels. The magnetic field lines can reconnect in the regions with the depleted density behind the sinking columns. It seems to be an explanation for such events as demonstrated in Fig. 1 and 3 and for bidirectional cases. During the event on 13-14 April, 2000 the deflection of coronal rays was caused by pass- 
ing of the CME. As a result a subsequent formation and downwards plasma blob motion was observed in nearest coronal region. This case, demonstrating a relation of sinking columns and CMEs, is discussed in detail by Sheeley and Wang [8]. There exists a correlation of the inflowing events with the cycle of the solar activity. The events are more frequent during the maximum of the solar activity. A relation with recurrent long-lived structures of the large-scaled magnetic fields on the Sun is observed, as it is indicated in [8]. Sinking plasma volumes, looking like columns or falling curtains, pairs of structures "up/down" can be explained by a reconnection model. As it is shown by Mann et al. [13] the most favourable conditions for magnetic field lines reconnection are evaluated to exist in high corona at the height of about $3.8 R_{\odot}$, that agrees with the results of the observations with the coronograph LASCO C2 SOHO.

The accelerations in the structures, observed as sinking plasma columns, are of the order of several $(2-6) \mathrm{m} \cdot \mathrm{s}^{-2}$ at the heights of $3-5 R_{\odot}$, i. e. less than gravitational (1130) $\mathrm{m} \cdot \mathrm{s}^{-2}$ at the same distances from the Sun. A matter fall results from joint action of different forces on the coronal plasma such as gravitation, magnetic and pushing forward or slowing down from surrounding matter flows.

Magnetohydrodynamic simulation of the process of a dense plasma blob falling in a vertical magnetic field has shown that a rarefaction region is formed behind the fallen material [14]. Dark tails, following the sinking plasma columns (as it is seen in Fig. 1 above), dark region between large arches, flying away (Fig. 3), seem to be volumes with density depletions.

Movements of the CME core fractions, returning back after lifting no higher than $5-6 R_{\odot}$ with accelerations changing in the range from $+30 \mathrm{~m} \cdot \mathrm{s}^{-2}$ to $-100 \mathrm{~m} \cdot \mathrm{s}^{-2}$, do not agree with the theory of the ballistically moving plasma. Observed accelerations do not correspond to gravitational ones. As it is demonstrated in [11] the trajectories, simulated with the consideration of gravitation, magnetic forces and interactions with the surrounding matter flows, can in principle explain observations with the LASCO C2 and C3 coronographs.

\section{SUMMARY}

So different types of inflowing and outflowing motions in the high corona have been considered and their characteristics such as morphology, velocities and accelerations, duration and relation with magnetic field structures are revised on the base of the published papers. The events are varied both by their characteristics and by their physical nature. Some types of motions is possible to explain by process of magnetic reconnection and some types of motions by combined action of the forces of gravitation, magnetic field and interaction with the background moving matter.

Acknowledgement. We are very thankful to Dr. N. R. Sheeley, Jr., Dr. Y.-M. Wang, and Dr. G. M. Simnett for their kind permission to use some LASCO/SOHO images of coronal events from their papers in our brief review.
[1] A. B. Delone, E. A. Makarova, Solar Phys. 45, 157 (1975).

[2] A. B. Delone, E. A. Makarova, G. V. Yakunina, Astrophys. Astron. 9, 41 (1988).

[3] A. B. Delone, G. V. Yakunina, G. A. Pofir'eva, Izv. Ross. Akad. Nauk, Ser. Fiz. 67, 381 (2003).

[4] N. R. Sheeley, Jr., T. N. Knudson, Y.-M. Wang, Astrophys. J. 546, L131 (2001).

[5] N. R. Sheeley, Jr., J. H. Walters, Y.-M. Wang, R. A. Howard, J. Geophys. Res. 104, 24,739 (1999).

[6] N. R. Sheeley, Jr. et al., Astrophys J. 484, 472 (1997).

[7] N. R. Sheeley, Jr., Y.-M. Wang, Astrophys. J. 562, L107 (2001).
[8] N. R. Sheeley, Jr., Y.-M. Wang, Astrophys. J. 579, 874 (2002).

[9] G. M. Simnett, Astron. Astrophys. 416, 759 (2004).

[10] Y.-M. Wang, N. R.Sheeley, Jr., D. G. Socker, R. A. Howard, N. B. Rich, J. Geophys. Res. 105, 25133 (1997).

[11] Y. M. Wang, N. R. Sheeley, Jr., Astrophys. J. 567, 1211 (2002).

[12] Y.-M. Wang et al., Astrophys. J. 498, L165 (1998).

[13] G. Mann, A. Klassen, H. Auras, H.-T. Classen, Astron. Astrophys. 400, 329 (2003).

[14] D. H. Mackay, K. Galsgaard, Solar Phys. 198, 289 (2001). 


\title{
СПОСТЕРЕЖЕННЯ ПОТОКІВ РЕЧОВИНИ В СОНЯЧНІЙ КОРОНІ, ОТРИМАНI HA LASCO SOHO
}

\author{
А. Б. Делоне, Г. А. Порфір'єва, Г. В. Якуніна \\ Державний астрономічний інститут ім. П. К. Штернберља, \\ Московсъкий університет, Москва, 119899, Росія
}

Наведено короткий огляд результатів спостережень потоків сонячної плазми, які видимі в білому світлі на коронографах C2 и C3 LASCO SOHO. Досліджено ділянку корони на відстанях $(2-6) R_{\odot}$ від центру диска Сонця. Розглянуто різні типи просторових структур потоків плазми, характеристики руху речовини, що напрямлені як до Сонця, так і від нього, та зв'язок з великомасштабною структурою магнетного поля. Швидкості речовини лежать у межах від декількох десятків до декількох сотень $\mathrm{km} \cdot \mathrm{s}^{-1}$. Обговорено можливі причини, які спричиняють виникнення низхідних та висхідних потоків плазми. Використано дані наукових публікацій та Інтернету. 